variable weight have a higher mortality, especially from cardiovascular disease. These observations present a problem to health educators who have been trying, without much success, to persuade people of the dangers to health of obesity. Should they continue to encourage people who are overweight to try to lose weight if they are only going to gain it again? Should advice on slimming be confined to people who are so severely obese that the complications of obesity ${ }^{4}$ outweigh the dangers of weight variation? Perhaps, on balance, the modest increase in average weight that is seen during adult life might be beneficial.

Four recent publications have clarified the picture. The nurses' health study recruited 121700 registered women nurses (almost all white) aged 30-55 in $1976 . .^{5}$ Of these, 115818 were initially free from diagnosed cardiovascular disease or cancer, but there were 991 non-fatal and 389 fatal myocardial infarcts during 14 years of follow up. After controlling for age, smoking, menopausal status, use of hormone replacement therapy, and parental history of heart disease, the study's authors found that the risk of myocardial infarction increased with increasing obesity-as measured by body mass index $(\mathrm{kg} / \mathrm{m} 2)^{1}$ )-and the increase began in what has been regarded as the "desirable" range. Compared with women with a body mass index below 21 , the relative risks (95\% confidence interval) for women with indexes of $21-23$, $23-25,25-29$, and $>29$ were $1 \cdot 19(0.98$ to $1 \cdot 44), 1 \cdot 46(1 \cdot 2$ to $1 \cdot 77), 2.06(1 \cdot 72$ to $2 \cdot 48)$, and $3.56(2.96$ to $4 \cdot 29)$ respectively. After adjustment for reported weight at age 18 years and the other risk factors, there was a clear increase in risk of myocardial infarction in women who gained more than $5 \mathrm{~kg}$ in weight after the age of 18 compared with those who did not: for weight gains of $5-8 \mathrm{~kg}, 8-11 \mathrm{~kg}, 11-19 \mathrm{~kg}$, and $\geqslant 20 \mathrm{~kg}$, the relative risks were $1.25(1.01$ to 1.55$), 1.65(1.33$ to $2 \cdot 05), 1.92$ (1.61 to $2 \cdot 29)$, and $2 \cdot 65(2 \cdot 17$ to $3 \cdot 22)$ respectively. ${ }^{5}$

In another report from the same study Manson et al analysed the relation of the body mass index to the mortality from all causes ( 4726 deaths). ${ }^{6}$ There was a familiar J shaped curve, with increased mortality above and below a body mass index of 20-27, which agrees with data from insurance societies and the American Cancer Society. ${ }^{7}$ However, when deaths in the first four years of the study and in women who smoked were removed from the analysis the number of deaths decreased to 1168 and the shape of the curve altered: the minimum mortality was found to be in the thinnest women, and multivariate relative risk increased with increasing weight. This strongly suggests that the J shaped curve with a nadir about an index of 25 is caused by deaths among smokers or those with pre-existing disease.

The conclusion to be drawn is that the relation of obesity to mortality (especially from heart disease) is probably one of increasing risk with increasing weight-or with increasing weight gain in adult life. The change in risk is small at first, but it becomes too great to be explained by chance above a body mass index of 27 or with a weight gain of more than $8 \mathrm{~kg}$ after the age of 18 .

The confounding effect of cigarette smoking and preexisting disease on the effect of weight loss was also shown in a report from the Honolulu heart program. ${ }^{8}$ During a six year follow up of 6537 Japanese American men aged 45-68, no association was found between mortality and loss of more than $4.5 \mathrm{~kg}$ weight, or weight fluctuation, among healthy men who had never smoked. Similarly, intentional weight loss among overweight white women who had never smoked and who had obesity related diseases was associated with decreased premature mortality. ${ }^{9}$

What advice flows from this research for those of us contemplating the feasting over the Christmas period? Most of us will probably gain a little weight, but this is not an important health risk if we do not smoke and are not obeseand if, when spring comes, we manage to drift back down to our pre-Christmas weight.

JS GARROW Editor

European fournal of Clinical Nutrition,

Rickmansworth WD3 2DQ

1 Rissanen AM, Heliövaara M, Knekt P, Reunanen A, Aromaa A. Determinants of weight gain and overweight in adult Finns. Eur f Clin Nutr 1991;45:419-30.

Wannameethee G, Shaper AG. Weight change in middle-aged British men: implications for health. Eur F Clin Nutr 1990;44:133-42.

3 Higgins M, D'Agostino R, Kannel W, Cobb J. Benefits and adverse effects of weight loss. Ann Intern Med 1993;119:758-63.

4 Garrow JS. Importance of obesity. $B M 7$ 1991:303:704-6.

5 Willett WC, Manson JE, Stampfer MJ, Colditz GA, Rosner B, Speizer FE, et al. Weight, weight change and coronary heart disease in women. $¥ A M A$ 1995;273:461-5.

6 Manson JE, Willett WC, Stamfer MJ, Colditz GA, Hunter DJ, Hankinson SE, et al. Body weight and mortality among women. N Engl f Med 1995;333:677-85.

7 Lew EA. Mortality and weight: insured lives and the American Cancer Society study. Ann Intern Med 1985;103:1024-9.

8 Iribarren C, Sharp DS, Burchfiel CM, Petrovitch H. Association of weight loss and weight fluctuation with mortality among Japanese American men. N Engl F Med 1995;333:686-92.

9 Williamson DF, Pamuk E, Thun M, Flanders D, Byers T, Heath C. Prospective study of intentional weight loss and mortality in never-smoking overweight US white women aged 40-64 years. Am f Epidemiol 1995;141:1128-41.

\title{
Doctors and commitment
}

\section{Nice work—shame about the job}

Doctors' working lives are changing radically. Out of hours cover by general practitioners, the new deal on hours of work for junior hospital doctors, and the changing roles and responsibilities of hospital specialists all raise important questions about commitment. How should we, as people with careers to follow and home lives to lead, balance patients' expectations and the demands of reorganised health care with the need for a satisfying and creative job? The patient, the service, the profession, or some higher ideal-to whom or what should doctors be committed, and to what extent?

The doctor-patient relationship is still central to our work. The recent document from the General Medical Council in Britain underlines that doctors must make the care of their patients their first concern. ${ }^{1}$ This encapsulates a principle of practice that has remained unchanged for over 2000 years and underpins the idea of what a doctor is. However, the context in which this relationship exists is changing so fast that a gap seems to have opened between the ideals of medicine and the realities of doctors' work experience. The "good enough" doctor can somehow never be good enough. Heath highlights the dilemma: "Time and trust are fundamental to our endeavours and both are being undermined in the current crisis." 2

Superficially, the answer may seem to lie in the contracts that clarify what a doctor should give or a patient may expect to receive. According to one registrar in general practice, the origin of our current difficulties is that "doctors offered everything on the basis that patients wouldn't ask too much" (J Thallon, personal communication). Contractual agreements may suit people who have a clear idea of what they need, or 
institutions with defined workloads and measurable outcomes, but they fit poorly with relationships in which needs change dramatically and continuity is important. The type of commitment required here is much more like a covenant, a promise made which has the fuzzy boundaries necessary for doctors' multitudinous roles. ${ }^{3}$ Contracts risk remaining locked into the negative aspects of obligation and of minimal expectation; an explicit but broader two way commitment can develop the positive aspects of care and re-empowerment of everyone involved.

How can this fit with the expressed commitment of health service managers to deliver high quality service? Performance indicators may be of limited use. ${ }^{4}$ In particular, they do not value the richness or variety of responses that professionals can offer. The tasks in health care are demanding, and healthcare workers need support on an individual or group basis. It is unclear where this support is coming from in today's NHS. It may be that re-evaluating roles and responsibilities within the new healthcare team will result in perceived loss. This must be balanced by potential gain, which an environment of "coercive healthism"-where the government's role of health protection is confused with the profession's role of health promotion-has not yet shown.'

When loyalty and commitment are challenged or broken, people feel betrayed. The reaction of many doctors to the uncomfortable process of setting new boundaries has been enormous hurt. This feeling has been expressed by resisting further change, low morale, endless moaning, a rise in the prevalance of stress, and evidence of burnout.

Understandably younger doctors have become increasingly reluctant to sign up for some career paths. This reassessment of what sort of job is worth doing is not confined to medicine: decline in trust and loyalty has been recognised in a variety of work environments. ${ }^{6}$ Doctors should be able to see medical work in transactional terms without losing their sense of vocation, and young doctors have something to teach their elders about keeping the patients central to their work while creating healthy boundaries between personal and professional life.

The NHS has received enormous loyalty from staff and patients. Whereas loyalty is based in the past, commitment looks to the future and is a conscious choice. Commitment must express what sort of people we want to be as well as what things it seems worth while to do. Although as doctors we are taught to take a good history from patients, our own histories often remain hidden from us. Hitherto we have not needed to be clear about our personal and professional needs and aims, but now we must recognise and explain what lies deeper than current economic or political fashion, and to make our goals explicit. As in Hirschmann's influential challenge to current market orthodoxy, in place of the prevailing culture of "exit" (leaving, closing down, or merging) we need to find our own loyal "voice" to criticise and improve the system while remaining within it. ${ }^{7}$

\section{Balancing act}

Yet a newly skilled and articulate generation will not eliminate the inevitable conflict between different spheres and types of commitment-home or work, patients or paperwork. A promise to give more to one implies a decision to give less to the other. A new task requires new time. The balance of competing commitments requires constant attention and adjustment to ensure the best use of scarce personal resources, including professional enthusiasm, constructive attention, and appropriate compassion. Such resources can be properly understood only in the context of a clear tradition, ${ }^{8}$ and doctors need the confidence to respect and defend their tradition to set the proper boundaries for a "do-able" job. Only if we value the diversity, energy, and creativity inherent in medical work are we likely to be able to ensure that our commitment flourishes and is transmitted to future generations.

CLARE VAUGHAN

Chair of South London Organisation of Vocational Training Schemes ROGER HIGGS

VTS Coordinator's Office,

St Thomas's Hospital,

London SE1 7EH

1 General Medical Council. Duties of a doctor: guidance from the General Medical Council. London: GMC, 1995.

2 Heath I. The mystery of general practice. London: Nuffield Provincial Hospitals Trust, 1995.

3 Campbell AV. Moderated love. London: SPCK, 1984.

4 Radical Statistics Health Group. NHS indicators of success: What do they tell us? BMF 1995;310:1045-9.

5 Skrabanek P. The death of humane medicine and the rise of coercive healthism. London: Social Affairs Unit, 1994.

6 Cannon D. Generation X and the new work ethic. London: Demos, 1994.

7 Hirschmann AO. Exit, voice, and loyalty. Cambridge, MA: Harvard University Press, 1970.

8 MacIntyre A. After virtue, a study in moral theory. London: Duckworth, 1990.

\section{The war on drugs}

\section{Prohibition isn't working—some legalisation will help}

Drugs, says psychiatrist Thomas Szasz, have taken over the lead role from sex in the "the grand morality play of human existence." "No longer," says Szasz, "are men, women, and children tempted, corrupted, and ruined by the irresistibly sweet pleasures of sex; instead, they are tempted, corrupted, and ruined by the irresistibly sweet pleasures of drugs." Because dealing with drugs is viewed as a moral problem, politicians tend to compete in their zeal to banish the evil from the kingdom. Those who talk of legalisation are dismissed as mavericks, and whipped back into line. The British government's drug strategy for the next three years states baldly "There will be no legalisation of any currently controlled drugs." ${ }^{\text {B }}$ But some legalisation would help.

The politicians fighting the jihad against drugs want to obliterate the enemy. They, of course, make an exception for legal drugs like alcohol, nicotine, and caffeine; indeed, the British government last week recommended tee totallers to take up drinking alcohol for the good of their health. ${ }^{3}$ Yet a world devoid of drugs seems as unlikely as a world devoid of poverty and sin. Thomas Sydenham observed 300 years ago that "Among the remedies which it has pleased Almighty God to give to man to relieve his sufferings, none is so universal and so efficacious as opium" (4); and Aldous Huxley wrote "That humanity at large will ever be able to dispense with Artificial Paradises seems very unlikely. Most men and women lead lives at the worst so painful, at the best so monotonous, poor and limited that the urge to escape, the longing to transcend themselves if only for a few moments, is and has always been one of the principal appetites of the soul.".5 